\title{
Uma prática edificante: \\ a carta do missionário jesuita ao rei de Portugal
}

\author{
An edifying practice: \\ a letter from a missionary jesuit to the king of Portugal
}

Moisés Laert Pinto Terceiro ${ }^{1}$

Joana Luiza Muylaert de Araújo ${ }^{2}$

Resumo: Este artigo apresenta elementos que compõem a prática epistolográfica dos jesuítas no antigo Estado do Maranhão e Grão-Pará, valendo de exemplo particular representado por uma carta do padre Antônio Vieira. A partir da leitura de observações feitas por autores como Alcir Pécora e João Adolfo Hansen, entre outros, este escrito intenta demonstrar e discutir o fato da epistolografia jesuítica se inserir em práticas discursivas correntes no tempo das missões em território da Colônia, em especial o século XVII. A demonstração dos elementos constitutivos da composição epistolográfica dos jesuítas ressalta o caráter mais edificante dessas cartas que factuais.

Palavras-chave: Antônio Vieira. Ars Dictaminis. Cartas jesuíticas.

Abstract: This article presents some elements that compose the Jesuits' epistle practice in the old State of Maranhão and Grão-Pará, using a particular example represented by a letter of Father Antônio Vieira. Stemming from observations by authors such as Alcir Pécora and João Adolfo Hansen, among others, the writing that proceeds attempts to demonstrate and to discuss the fact that the Jesuit letters are inserted in discursive practices current at the time of the missions in the territory of the colony, especially in the 17th century. The demonstration of the constituent elements of the Jesuit epistolography emphasizes more the edifying character of those letters than the factual one.

Keywords: Antônio Vieira. Ars Dictaminis. Jesuit epistolography.

1 Mestre em Estudos Literários pelo Programa de Pós-Graduação em Estudos Literários da Universidade Federal de Uberlândia - UFU.

2 Professora Doutora Joana Luiza Muylaert de Araújo, docente titular do Programa de Pós-Graduação em Estudos Literários da Universidade Federal de Uberlândia - UFU. 
Moisés Laert

Pinto Terceiro

Joana Luiza

Muylaert de

Araújo

140

\section{Epistolografia Jesuítica}

Nas muitas cartas escritas pelo jesuíta Antônio Vieira (1608-1697), cujos destinatários vão de padres da Companhia de Jesus a altas autoridades da corte portuguesa, notam-se preocupações recorrentes, como a constante reclamação pela falta párocos e curas que celebrem os sacramentos nos territórios da missão e a manifesta pretensão em ver a Ordem de Santo Inácio exercer o monopólio da administração dos índios; mais que preocupações, são igualmente recorrentes os procedimentos retóricos usados por Vieira para compor o relato dessas suas preocupações.

Isso porque a prática epistolográfica mantida pelo missionário não revela a expressão individual de uma subjetividade isolada; antes se insere em um quadro retórico-temático mais amplo, dentro do qual Vieira não é o único, senão mais um dentre as partes que formam o corpo místico dos jesuítas. As cartas, por conseguinte, em constante circulação à época das missões chefiadas por Vieira, têm formas e funções bem definidas, as quais, mobilizadas pelo remetente, apontam o caminho de sua inteligibilidade ao destinatário eleito.

Para João Adolfo Hansen (2008), quando se trata das cartas de Antônio Vieira, "é conveniente especificar a historicidade dos seus regimes discursivos." (HANSEN, 2008, p.265), uma vez que não são informais. Enquanto instrumentos da ação missionária, essas cartas serão mais que portadoras de notícias, pois "funcionam como dispositivos de conhecimento da terra, catequese e controle dos índios, colonos e padres." (HANSEN, 2005, p.15). Sua composição é tributária do modelo histórico da Ars Dictaminis, a arte de escrever cartas, cujos preceitos são aplicados a partir da apropriação que deles se fez pela Companhia de Jesus.

Assim, o conjunto de temas surgido a partir da experiência religiosa dos missionários recebe o tratamento retórico prescrito pela tradição epistolar ainda em uso no tempo de Vieira. O conteúdo das cartas em toda sua complexidade "são funções estritas dessa acomodação ao gênero” (CARDOSO E PÉCORA, 2012, p.2).

Certamente essa é uma das razões para que esses escritos não sejam vistos como portadores de uma "verdade" histórica atestada documentalmente. $\mathrm{O}$ jogo retórico empregado nessas cartas, orientado pela preceptiva inaciana, abre as cortinas do teatro verbal onde acontecimentos e seus personagens compõem a peça cuja encenação retórica ora se abre a aplausos ora se precipita em lágrimas a depender de quem e para quem será exibido o espetáculo. Nesse sentido, não será exces- 
so de precaução repetir aquilo que Cardoso e Pécora já advertiram: “A leitura criteriosa e sistemática desse material sugere uma relação de independência entre o que é escrito e o que supostamente aconteceu." (CARDOSO E PÉCORA, 2012, p.12).

As orientações de Inácio de Loyola (1491-1556) aos padres da Companhia trazem explícitas indicações a respeito da troca de cartas entre os religiosos. Aponta o Fundador da Ordem, ainda segundo Pécora (2001, p.29), que, ao escrever, os missionários fizessem uma "carta principal que se pudesse mostrar a qualquer pessoa", estando cientes de que o curioso da vez poderia integrar "pessoas principais" de Roma, tornando, pois, conveniente à carta "guardar ordem", evitando, assim, trazer "coisas impertinentes", precauções necessárias para que a leitura das cartas pudesse dar "edificação a quem as lesse".

Uma prática edificante ainda no século XVII acusações de adversários, os quais insinuavam não haver "verdade" nas missivas cujos autores fossem membros da Companhia de Jesus. A esse respeito nos informam Cardoso e Pécora (2012, p.13), ao citar que tal acusação fora realizada por Frei Cristóvão de Lisboa, líder dos franciscanos presentes no Maranhão e Grão-Pará. O Frei ainda reclamava maiores créditos às cartas franciscanas, reputadas por ele como mais "verdadeiras" em oposição àquelas escritas pelos irmãos da Ordem de Santo Inácio.

A disputa entre Ordens religiosas, capaz de expor contradições próprias do processo colonizador em terras brasileiras, apresenta também maneiras distintas de conceber a experiência missionária, e mais que isso, diferentes formas de registrá-la, compreendidas a partir de apropriações próprias da tradição epistolar.

No caso dos jesuítas, por exemplo, as diversas cartas que escreveram cumpriam além da função de informar sobre eventos, lugares, pessoas e práticas difundidas nas inúmeras missões em curso pelo mundo; reforçar entre irmãos de Ordem, liados pela troca de cartas, os laços de solidariedade criados pelos métodos compartilhados, valorizados pela rede estabelecida pela prática epistolográfica capaz de unir os missionários dispersos pelo mundo em um mesmo clamor de fé. Essa experiência místico-devocional é também um dos elementos indissociáveis que ajudam a compor a carta jesuítica, a partir do qual as circunstâncias particulares da ação missionária acomodam-se "ao modelo retórico e preceitos escolásticos do período." (CARDOSO E PÉCORA, 2012, p.14). 
Moisés Laert

Pinto Terceiro

Joana Luiza

Muylaert de

Araújo

142

Torna-se conveniente, portanto, avaliar as cartas escritas por jesuítas nos séculos XVI, XVII e XVIII como parte fundamental de uma prática simbólica cujas bases se assentam em uma visão profética do mundo que sustentava a disposição dos missionários na busca de seu objetivo último: a conversão da gentilidade de todos os rincões da terra.

Exemplos capazes de demonstrar fracassos e sucessos, tristezas e alegrias, expectativas e frustrações, que bem ilustram a experiência particular na missão, podem-se colher em cartas nascidas da pena de Antônio Vieira. Nelas se encontram diversas rotas a compor "um mapa retórico em progresso", Pécora (2001, p.18), no qual cabem os muitos desafios trilhados pelo missionário nos tortuosos caminhos da conversão.

\section{Uma carta}

Em carta remetida do a Dom João IV (1604-1656), então rei de Portugal, no ano de 1653, Vieira atualiza o monarca a respeito dos assuntos da Colônia. Como Superior das missões do Maranhão, de Macapá e do Grão-Pará, o jesuíta discorre sobre a vida sem regras dos colonos e o martírio dos índios, os quais, segundo defende junto ao rei, estariam bem protegidos e melhor serviriam a Coroa se a tutela de suas vidas estivesse sob o governo local da Companhia de Jesus.

A missiva em questão apresenta os cumprimentos de praxe, respeita o lugar na ordem social dos participantes da conversa, e está disposta segundo as partes principais prenunciadas pela ars dictaminis, quais sejam: salutatio (saudação), captatio benevolentiae (obtenção da simpatia), narratio (narração), petitio (requerimento) e conclusio (fecho).

No caso de Vieira, a saudação que abre o exórdio da carta é costumeiramente simples, procedimento mantido na missiva eleita como exemplo. Mesmo se tratando da posição do destinatário, o soberano de Portugal, a brevidade da saudação não fere a hierarquia, posto que, na carta, sua função se entende como "aplicação de uma fórmula piedosa" (CARDOSO E PÉCORA, 2012, p.2). "Senhor meu”, “Meu Senhor”, “Exmo. Senhor" são formas usuais de se dirigir a um interlocutor.

Ademais, como já orientava as "Regras para escrever cartas", do Anônimo de Bolonha: "A saudação é uma expressão de cortesia que transmite um sentimento amistoso compatível com a ordem social das pessoas envolvidas." (ANÔNIMO DE BOLONHA, 2005, p.84). Respeitando- 
-se, portanto, a ordem social do destinatário, o tom comum a empregar-se em uma carta, deve ser o do cumprimento cortês, o que se verifica, tratando-se da abertura da carta de Antônio Vieira.

$\mathrm{Na}$ segunda parte do exórdio está presente a captatio benevolentiae, procedimento por meio do qual o remetente "busca a disposição favorável do leitor para o que há de ler em seguida." (CARDOSO E PÉCORA, 2012, p.3). Nesse ponto da composição os recursos utilizados pelo remetente são variados, todavia, geralmente instituem uma representação de humildade que recai sobre o autor da carta, o qual se mostra abaixo do destinatário a partir da exaltação deste de modo a apresentá-lo como pessoa superior ao mandante da epístola. É segura maneira de conquistar a simpatia do leitor da missiva.

Uma prática edificante

\begin{abstract}
Senhor. - Como V.M. foi servido encomendar-me tão particularmente a conversão da gentilidade deste Estado, e a conservação e aumento de nossa santa fé nele, faltaria eu muito a esta obrigação, e à da consciência, se não desse conta a V.M. dos grandes desamparos espirituais que em todas estas partes se padecem, apontando com toda brevidade que me for possível os danos e causas deles, e os remédios com que se lhe pode acudir. (VIEIRA, 2008, p.236).
\end{abstract}

No trecho acima, da carta em destaque, é notável os procedimentos associados da saudação, "Senhor", e da conquista da simpatia, "faltaria eu muito a esta obrigação, e à da consciência, se não desse conta a V.M.". A abertura da carta composta a partir das preceptivas adequadas expõe já de início os assuntos a serem tratados adiante. A breve saudação é responsável pela instituição de um tom ameno, o qual se reforça pelo expediente de busca da disposição favorável do leitor, esta ilustrada pelo excerto no qual o padre insinua uma falta pessoal que ora se atenua pelo relato enviado ao monarca. Segundo o Anônimo de Bolonha (2005): “A boa disposição pode ser assegurada pela pessoa que envia a carta se menciona humildemente alguma coisa sobre seus negócios, ou suas obrigações, ou suas razões." (ANÔNIMO DE BOLONHA, 2005, p.97).

A falta em questão, componente discursivo a expressar caráter humilde do missivista, atentaria em última análise com a encomenda feita pelo rei ao religioso, conforme este sugere na carta. A encomenda em si: “a conversão da gentilidade deste Estado, e a conservação e 
Moisés Laert

Pinto Terceiro

Joana Luiza

Muylaert de

Araújo

144

aumento de nossa santa fé" (VIEIRA, 2008, p.236), encontra obstáculos não transpostos solitariamente pelo jesuíta, impondo ao religioso o dever de solicitar a intervenção real para removê-los do caminho da ação missionária sem a qual a encomenda não se cumpre. Os "desamparos espirituais" cujos danos e causas serão apontados "com toda a brevidade" formarão o objeto do relato apurado a compor a narração presente na missiva.

$\mathrm{Na}$ terceira parte da carta estão reunidos os procedimentos da narratio que, no caso da narração empreendida por Vieira, esforça-se por construir o relato detalhado que compõe a maior parte da missiva. É nessa parte que o remetente apresenta "um quadro temático", no qual os acontecimentos são selecionados para servirem de exemplo da permanência de determinadas situações capazes de indicar o roteiro de costumes e práticas estabelecidos. Nas palavras de Cardoso e Pécora (2012): "Os quadros temáticos mais simples são compostos como diagnóstico da situação geral em que se encontra o Brasil." (CARDOSO E PÉCORA, 2012, p.5).

No trecho que segue, o qual compreende parte da carta reservada à narração, Vieira traça as premissas fundamentais do relato que apresenta ao rei:

Os moradores deste novo mundo, que assim se pode chamar, ou são portugueses ou índios naturais da terra. Os índios, uns são gentios que vivem nos sertões, infinitos no número e diversidade de línguas; outros são pela maior parte cristãos, que vivem entre os portugueses. (VIEIRA, 2008, p.236).

O relato se inicia pela tópica do "novo mundo", a qual se difunde pela ideia geral de que na "terra nova" tudo há para ser desbravado. Essa tópica remonta também a um inventário positivo responsável pela representação das "terras brasileiras" como naturalmente férteis, fertilidade essa não extensiva somente ao chão do novo território, mas também às possibilidades de extensão da própria fé, cujos frutos facilmente frutificarão caso a semeadura seja bem realizada.

No caso específico da narração realizada por Vieira interessa mais o habitante natural dessa terra, cuja alma incauta aguarda a intervenção da Igreja, salvando-se, assim, do pecado de morrer sem o batismo cristão. A narração se inicia pela indicação dos “moradores deste 
novo mundo", estabelecendo uma dualidade entre os naturais da terra, isto é, os índios, e por oposição, os não naturais, os portugueses. Essa dualidade conflitiva é o mote a partir do qual os "desamparos espirituais" encontram sua melhor demonstração.

\footnotetext{
Os portugueses, Senhor, vivem nestas partes em necessidade espiritual pouco menos que extrema, com grande falta de doutrina e de sacramentos, havendo muitos deles que não ouvem missa nem pregação em todo o ano por a não terem, nem sabem os dias santos para os guardarem, nem os guardam, ainda que os saibam, nem há quem a isso os obrigue; o qual desamparo é ainda maior nas mulheres, filhos e filhas, morrendo não poucas vezes uns e outros sem confissão. (VIEIRA, 2008, p.236).
}

Uma prática edificante

Ainda que o "novo mundo" aponte para um quadro favorável à conversão dos naturais da "terra nova", posto serem esses, tal qual o fértil território que ocupam, tendentes naturalmente à aceitação da palavra de Deus, o forasteiro, representado pelo colono português tornou-se um obstáculo, exaustivamente apontado pelo missivista, já que "quando o quadro da potência da terra cruza com o dos costumes, das gentes que nela vivem, o quadro positivo colapsa." (CARDOSO E PÉCORA, 2012, p.5-6).

Delineado o problema responsável pelos entraves à conversão do gentio, passa Vieira a apresentar os seus pormenores, os quais, no mais das vezes, revelam "um retrato baixíssimo do português, no qual avulta a covardia." (CARDOSO E PÉCORA, 2012, p.6). A carta, portanto, vai compondo uma sucessão de vícios e maus costumes dos portugueses cuja perfídia demonstra a doença para a qual o missionário jesuíta clama remédios ao rei.

A causa dos desamparos, portanto, como Vieira busca ilustrar, é a falta de doutrina e sacramentos, sem os quais os portugueses quedam em extrema necessidade espiritual. Essa falta se agrava na medida em que não há missas e pregação disponíveis aos colonos. A situação fica ainda pior por não haver quem possa obrigar os portugueses a se manterem vigilantes com a doutrina. Esboçada a causa da extrema necessidade espiritual em que vivem os portugueses no Brasil, passa Vieira a propor solução: 
Moisés Laert

Pinto Terceiro

Joana Luiza

Muylaert de

Araújo
O remédio deste gravíssimo dano é o multiplicarem-se as igrejas e curas, nos lugares que parecerem mais acomodados; haver uma pessoa eclesiástica de letras e zelo, que seja administrador de todo este Estado, ou tenha outro gênero de superintendência sobre o espiritual de todo ele, como há no Rio de Janeiro; ou ao menos que, para suprir todas estas faltas, se mande número bastante de religiosos, que tenham por instituto a salvação das almas, e que sejam pessoas observantes do tal instituto; porque o que tem feito grande mal a este Estado são homens religiosos de vida e doutrina pouco ajustada. (VIEIRA, 2008, p. 237).

Se a causa das mazelas que gera vícios entre os portugueses está fundamentalmente associada à falta de religiosos responsáveis pela observação rigorosa do respeito à doutrina e aos sacramentos, naturalmente o unguento capaz de pôr fim a moléstia é a abertura de novas igrejas na Colônia, com multiplicação de religiosos que delas possam zelar. E que o monarca português, caso atenda ao pedido, observe se os religiosos destinados à tarefa sejam pessoas "de letras e zelo", já que "homens religiosos de vida e doutrina pouco ajustada" não só já vivem no Brasil, como são uma das causas do mal provocado a este Estado.

Nesse ponto da narração o tema dos maus costumes de cristãos abre portas às acusações que Vieira tece a outros religiosos cujas condutas, em sua avaliação, devem ser condenadas, por serem reprováveis. Trata-se de elemento recorrente em sua correspondência, com lugar cativo nas narrações de suas missivas. Sobre tal recorrência, comentam Cardoso e Pécora (2012):

O mau costume dos cristãos toma a sua pior forma quando as cartas descrevem o modo de vida dos clérigos de outras Ordens, em quem tudo, sem exceção, parece contrário à religião e à eficácia da pregação: são maus exemplos para todos e descrédito da fé católica; absolvem levianamente moradores em pecado mortal; cobram pelo ofício da missa; não pregam, nem convertem. (CARDOSO E PÉCORA, 2012, p.6).

Estes "homens religiosos de vida e doutrina pouco ajustada" não concorrem com sua parte na tarefa precípua da conversão. Já que esses religiosos "não pregam, nem convertem", missão funda- 
mental aos que no "novo mundo" aportaram, sua contribuição longe de engrandecer o trabalho da Igreja, antes o desmerece e o atrapalha. Agindo, assim, demonstram seu compromisso com o pecado, não com a salvação.

E não apenas os portugueses ajudam a compor o conjunto dos relatos presentes na narração da carta escrita por Antônio Vieira. A outra ponta da dualidade acima estabelecida também recebe o cuidado da narrativa do jesuíta. Se por um lado os maus costumes dos portugueses criam muitos embaraços ao regular exercício da conversão, por outro há sujeitos que, acima de outros, necessitam, na visão do missionário, dos mais básicos preceitos da fé. O estado dos índios no Brasil é assim relatado por Vieira a Dom João IV:

Uma prática edificante

\begin{abstract}
Os índios que vivem em casa dos portugueses, pela miséria de seu estado, e pela natural rudeza de quase todos, ainda em muito maior parte lhes tocam todos os desamparos espirituais acima referidos. Muitos deles vivem e morrem pagãos, sem seus senhores nem párocos lhes procurarem batismo, nem fazerem escrúpulo disso. (VIEIRA, 2008, p.237).
\end{abstract}

Se os portugueses são acometidos por desamparos espirituais, logo os índios, submetidos que estão aos portugueses, também padecem do mesmo mal, com o inconveniente de serem o elo mais fragilizado dessa relação. Nota-se que a causa do desamparo é a mesma, cabendo a este ponto da narração demonstrar uma espécie de agravamento dos efeitos nocivos da falta de religiosos no local. Esse procedimento cumpre bem a função a que se destina, vez que é na narração que o remetente cria um "lugar argumentativo", ou seja, um espaço no qual os dados favoráveis às premissas defendidas são mobilizados.

E ao trazer os índios ao centro de suas argumentações, Vieira mobiliza outro conjunto de tópicas recorrentes em sua epistolografia, aquele "que visa demonstrar as disposições favoráveis dos índios à adoção da fé católica." (CARDOSO E PÉCORA, 2012, p.8). Nesse sentido, mais urgente ainda resta o conserto dos males existentes na Colônia, já que os maus costumes relatados criam empecilhos à tarefa precípua dos missionários. A boa notícia fica por conta de que as más práticas observadas em solo brasileiro não significam que a natureza das pessoas é má, o que, em relação aos índios, torna-se o maior impulso para a 
Moisés Laert

Pinto Terceiro

Joana Luiza

Muylaert de

Araújo

148

continuação da atividade missionária, e justo nesta "diferença que reside o fundamento teológico da conversão e da intervenção jesuítica." (CARDOSO E PÉCORA, 2012, p.8).

Todas essas preocupações transformadas em argumentos a partir da narração cumprem, na composição da carta remetida por Vieira ao monarca português, papel importante no estabelecimento de interlocução entre remetente e destinatário, já que:

\footnotetext{
O destinatário delas recebe não só os temas representados, mas também os preceitos doutrinários aplicados para representá-los e interpretá-los, sendo composto como função e reconhecimento da preceptiva retórica e da doutrina teológico-política que
} dão forma às matérias. (HANSEN, 2003, p.17-18).

A doutrina teológico-política que une o missivista a seu distinto leitor reforça entre eles laços de hierarquia, assim como pavimenta o terreno para a justa intervenção do monarca. A ação do jesuíta em terras portuguesas de além-mar é tarefa própria do religioso, dentre as obrigações que lhe cabe no cumprimento daquela doutrina. A conversão do índio passa pela obrigação da Companhia de Jesus de reiterar a unidade de seu corpo místico, nele integrando o índio convertido, conforme lhe encomendara o próprio Dom João IV, visto ser este a cabeça daquele místico corpo; reconhecido por todos que parte dele fazem a partir do pacto de sujeição à pessoa fictícia do rei.

Para encerrar a narração, após Vieira nela ter construído o relato do "estado de coisas" que acometem à Colônia, um último esforço narrativo é apresentado:

Isto é, Senhor, o que me pareceu representar a V.M., por satisfazer à minha obrigação e por desencargo da minha consciência, encarregando muito, com toda a submissão que devo à de V.M, o remédio destes gravíssimos danos que padecem tão infinitas almas, de todas as quais Deus há de pedir conta a V.M., e muito maior depois de chegarem às reais mãos de V.M. estas notícias, não de ouvidas, mas de vistas, e experiência mandadas por quem V.M. muito bem conhece que não veio buscar ao Maranhão mais que o maior serviço e glória de Deus, e que abaixo d'Ele nenhuma cousa procurou nunca nem amou tanto como o serviço de V.M. (VIEIRA, 2008, p.241). 
Nele Vieira recorda a responsabilidade do rei para com seus súditos, lembrança que é realizada com o decoro e respeito que são componentes da carta. Essa responsabilidade é verticalizada por Vieira quando este a vincula às obrigações do monarca com Deus, fazendo constar que o Criador certamente pedirá conta do padecimento das almas não socorridas por quem delas fosse responsável. Tal vinculação é mais um elemento a reforçar o conjunto de argumentos mobilizados pelo jesuíta durante o procedimento da narração, a qual acarreta maior peso em futura decisão do soberano português.

Concluída a terceira parte da carta, verifica-se que a narração não apenas expõe um "estado de coisas", cuja exposição detalhada ajuda a ilustrar os problemas para os quais o missivista busca remédio, e no qual se cria um "lugar argumentativo", espaço onde os argumentos

Uma prática edificante favoráveis à pretensão do remetente se sucedem, mas também cumpre outra importante função, que é "a sustentação eficaz da petitio, isto é, as várias solicitações efetuadas pela carta às autoridades competentes." (CARDOSO E PÉCORA, 2012, p.9-10).

Importante pontuar que o pedido não ocupa lugar fixo na carta, podendo ser realizado em diversos momentos da composição. No caso da carta que ora se observa, foi possível notar que o requerimento a ser submetido ao rei permeou toda a extensão da narração quando esta reiterava causas e efeitos para os quais dado remédio já se apresentava. A petitio, por conseguinte, garante "o ciclo de estreitamento de laços devocionais" (CARDOSO E PÉCORA, 2012, p.10-11), pois obriga o destinatário a pronunciar-se acerca do requerimento que lhe fora submetido à análise.

No caso em comento, ao final do procedimento narrativo, solicitação explícita é feita ao rei:

Pelo que, Rei e Senhor, prostrados aos reais pés de V.M., e em nome de todas as almas que nestas vastíssimas terras de V.M. estão continuamente descendo ao Inferno, por falta de quem as doutrine, pedem elas e pedimos os poucos religiosos que cá estamos, pelo sangue de Cristo com que foram remidas, que sirva V.M. de nos mandar mais companheiros, com quem continuemos e aumentemos o começado [...]. (VIEIRA, 2008, p.242). 
Moisés Laert

Pinto Terceiro

Joana Luiza

Muylaert de

Araújo

150

O pedido de envio de "mais companheiros" religiosos que sigam as especificações detalhadas na narração conforma o requerimento submetido ao monarca cujo deferimento encontra no procedimento da narratio as razões de decidir.

Na sequência da petitio segue o encerramento da carta com a conclusio que põe fim à missiva. É comum à conclusão aplicar novamente o pedido construído no curso da narrativa epistolar, acrescentando a ele bênçãos e orações. No caso da carta enviada por Vieira a Dom João IV, o encerramento se expressa pelo oferecimento contínuo de sacrifícios dos missionários na Colônia em favor da conservação e aumento do reino: "e todas as almas que por nosso meio se salvarem farão no Céu a Deus a mesma oração." (VIEIRA, 2008, p.242). .

O fechamento expresso na carta, a qual se finaliza por desejos de graça ao monarca, sugere um futuro gracioso ao rei caso este atenda o requerimento que lhe fora submetido. Tal procedimento não deixa de legar à carta fé no futuro, tanto na espera do deferimento real aos pedidos realizados, quanto nos efeitos positivos que o deferimento gerará. Acerca da esperança como parte da composição epistolar jesuítica, assim se manifestam Cardoso e Pécora (2012):

\footnotetext{
A esperança é componente técnico da carta jesuítica. A graça do futuro é sempre a melhor fiança da empresa em novas terras, por meio da realimentação presente da disciplina da vontade e da prática devocional. As cartas são parte da produção da esperança, o que se acentua nas conclusões, que usualmente prometem a continuidade da correspondência. (CARDOSO E PÉCORA, 2012, p.11).
}

Desse modo, as cartas tomam parte no cultivo da boa espera, cabendo aos missivistas usarem-nas no plantio. 0 fecho da carta enseja a espera de melhores dias futuros, que poderão mais facilmente ser alcançados após a decisiva ação do rei em favor da missão. A carta assim concluída também deixa aberta a rota pela qual a continuidade do tráfego epistolográfico se mantém pela constante viagem de notícias que, pelas cartas, vêm e vão.

\section{Conclusio}

O conjunto das cartas jesuíticas que foram produzidas durante o período em que a Companhia de Jesus esteve à frente do processo de evangelização dos gentis em terras brasileiras, certamente, tem informações preciosas 
para quem busca algum entendimento acerca das contradições próprias do processo de Colonização. Sua leitura é atitude honesta de quem procura conhecer melindres das ações de agentes diretos da empresa colonial.

Mas, como parte do divertimento da viagem reside na estrada, e não apenas no destino, forçoso é ao observador atento orientar-se no caminho para não se perder antes mesmo da chegada. As cartas dos missionários são mais que conteúdo, suas linhas não somente contam histórias muitas, mas se dispõem a contá-las de determinada maneira, cuja forma de se dispor já é conhecida do contador antes que a história esteja pronta.

Assim, a riqueza possível de se extrair, em termos de análise, das missivas disponíveis, alcança vulto quando essas cartas passam pelo crivo de seus observadores sem estarem dissociadas do mundo simbólico onde puderam circular e produzir sentido. $O$ trato retórico a que se

Uma prática edificante submetiam faz das cartas da Companhia de Jesus, entre elas as do padre Antônio Vieira, escritos tendentes a gerar determinados efeitos em seus receptores, os quais certamente não são obra da espontaneidade subjetiva dos sujeitos, mas sim trabalho meticuloso, previamente orientado por preceptivas retóricas cujas funções eram determinadas tanto pelos tratados reguladores dos gêneros letrados da época, quanto pelas razões teológico-políticas sustentadoras da "missão histórica" do reino português: converter os gentios em todas as partes do mundo.

Cabendo aos missionários jesuítas esta tarefa cristã, suas cartas foram instrumentos da conversão, cuidadosamente elaboradas, atentas aos objetivos a se auferirem, e profundamente ligadas à prática devocional comum a religiosos. Mais que informar, essas cartas buscavam persuadir, e não só, tinham por intuito também a edificação, sendo que a "verdade" nelas presente não se confunde com o manejo de um dado objetivo, mas de uma "versão cristã", ou jesuíta, dos acontecimentos. 


\section{REFERÊNCIAS}

Moisés Laert

Pinto Terceiro

Joana Luiza

Muylaert de

Araújo

152
ANÔNIMO (de Bolonha). Regras para Escrever cartas. In: A Arte de Escrever cartas: Anônimo de Bolonha, Erasmo de Rotterdam, Justo Lípsio. Organizado e traduzido por Emerson Tin. Campinas SP: Editora da UNICAMP, 2005, p.81-109.

CARDOSO, Alírio e PÉCORA, Alcir. Uma Arte Perdida nos Trópicos: a epistolografia jesuítica no Maranhão e Grão-Pará (séculos XVII

- XVIII). Revista Estudos Amazônicos, Belém PA, vol.VIII, nº 2, p.1-22, 2012.

HANSEN, João Adolfo. A escrita da conversão. In: Diálogos da Conversão, missionários, índios, negros e judeus no contexto ibero-americano do período barroco. Organizado por Lúcia Helena Costigan. Campinas SP: Editora da UNICAMP, 2005, p.15-43.

João Adolfo. Para ler as cartas do Pe. Antônio Vieira (16261697). Teresa revista de Literatura Brasileira [8 9], São Paulo SP, p.264-299, 2008.

PÉCORA, Alcir. A arte das cartas jesuíticas do Brasil. In: Máquina de Gêneros. Campinas SP: EDUSP, 2001, p.17-68.

VIEIRA, Antônio. Cartas - Volume 1. Organizado por João Lúcio de Azevedo. São Paulo SP: Editora Globo, 2008, p.236-242. 